\title{
Objetos de Aprendizagem para professores da Ciberinfância
}

\author{
Profa. Dra. Patricia A. Behar ${ }^{1}$, \\ Profa. Dra. Leni Vieira Dornelles ${ }^{2}$, \\ $\mathrm{Msc}^{\text {anda }}$. Caroline Bohrer do Amaral ${ }^{1}$, \\ $\mathrm{Msc}^{\text {anda }}$ Ana Paula Frozi de Castro e Souza ${ }^{1}$ \\ ${ }^{1}$ Faculdade de Educação (FACED)/Núcleo de Tecnologia Digital aplicada à Educação \\ (NUTED) - Universidade Federal do Rio Grande do Sul (UFRGS) \\ Porto Alegre - RS - Brasil \\ ${ }^{2}$ Faculdade de Educação (FACED)/Grupo de Estudos em Educação Infantil (GEIN) \\ Porto Alegre - RS - Brasil \\ pbehar@terra.com.br, ledornel@redemeta.com.br, carol.bba@gmail.com, \\ nanafrozi@yahoo.com.br
}

\section{Learning Objects for Cyber-childhood's Teachers}

\begin{abstract}
The current article deals with the creation and use of learning objects in the development of teachers of kindergarten and elementary school. In this perspective, issues about cyber-childhood, new demands in the teaching of childs, the possibility of the formation of theachers supported by learning objects, and the presentation of learning objects created by a UFRGS resarch group are discussed. After that, the experience gained by the group in extension courses are reported, focused at the validation of the learning objects and the training of teachers to the cyber-childhood.
\end{abstract}

Resumo. O presente artigo trata do desenvolvimento e utilização de objetos de aprendizagem (OAs) na formação de professores de Educação Infantil e Anos Iniciais do Ensino Fundamental. Nesta perspectiva, serão abordadas questões acerca da ciberinfância e as novas demandas da educação de crianças, a possibilidade de formação de professores com auxílio de OAs, bem como a apresentação de OAs desenvolvidos por um grupo de pesquisa da Universidade Federal do Rio Grande do Sul. Ao final, relata-se a experiência do grupo em cursos de extensão, visando a validação dos OAs e a formação de professores para a ciberinfância.

\section{Introdução}

As tecnologias da informação e da comunicação (TIC's) estão cada vez mais presentes na sala de aula, remetendo professores e alunos a uma nova relação com o saber e com a aprendizagem. Novos desafios e paradigmas relacionados à informática surgem todos os dias no cotidiano do professor. Este, por sua vez, precisa estar atento às atuais demandas trazidas por seus alunos, refletindo constantemente sobre sua prática pedagógica, abrangendo as possibilidades de trabalho educativo, possibilitado pelas TIC's. 
Uma das novas demandas da Educação Infantil e Anos Iniciais do Ensino Fundamental refere-se a um novo tipo de infância decorrente do advento da informática: a ciberinfância (DORNELLES, 1995). Esta diz respeito às crianças, que também podem ser chamadas de ciberinfantes, que nascem em contato com a tecnologia e não conseguem imaginar o mundo sem estes recursos. Esses ciberinfantes manipulam facilmente os aparelhos eletrônicos, dispensando, muitas vezes, qualquer instrução. A forma como elas utilizam os recursos tecnológicos digitais é bastante pessoal e está ligada, na maioria das vezes, a atividades de lazer. No entanto, a tecnologia pode oferecer muito mais recursos às crianças e à educação.

Dessa forma, acredita-se que os educadores precisam se aproximar mais dos interesses do seu público e aperfeiçoar-se, aprendendo também a utilizar e dominar as tecnologias. Precisam também confrontar suas práticas com novas formas de se trabalhar, valorizando a não-linearidade de conteúdo e o trabalho a partir da perspectiva do aluno. Assim, visando a formação de professores os objetos de aprendizagem (OA) apresentam-se como uma possibilidade de disponibilizar conteúdos de forma mais dinâmica e atraente na Internet. Nesse sentido, tem-se realizado estudos para o desenvolvimento desses materiais, enfocando temáticas contemporâneas relativas à ciberinfância, práticas pedagógicas, utilizando recursos tecnológicos digitais, cultura e aprendizagem. O principal objetivo deste projeto é contribuir para a atualização e reflexão dos professores em serviço, visibilizando a aplicação das tecnologias digitais na realidade escolar.

Nessa perspectiva, uma equipe de educadores e webdesignes do Núcleo de Tecnologia Digital aplicada à Educação (NUTED), juntamente com o Grupo de Estudos da Infância (GEIN), têm pesquisado e desenvolvido objetos de aprendizagem para atualização de professores de Educação Infantil e Séries Iniciais. Para a estruturação dos OAs, segue-se os padrões do RIVED ${ }^{1}$, um site referente a um programa do governo que incentiva a produção de objetos de aprendizagem e os publica na Web. E para a disponibilização, esses foram cadastrados no repositório Coletânea de Entidades de Suporte ao uso de Tecnologia na Aprendizagem (CESTA), onde os professores têm fácil acesso por meio de busca.

À medida que um objeto de aprendizagem é construído, requer-se a sua validação. Assim, ao longo dos projetos estão sendo oferecidos cursos de extensão para professores, contribuindo para a formação de professores nas temáticas dos OAs e para uma aproximação desses sujeitos com os recursos da internet.

\section{A formação de professores para a ciberinfância}

Atualmente, os espaços infantis vêm sofrendo grandes mudanças, reconfigurando as noções de tempo e espaço destas crianças. É o que Prensky (2001), define como os nativos digitais. Pessoas que nasceram em contato com a tecnologia e não conseguem imaginar a comunicação antes dela, estabelecendo novas formas de relação com o mundo. Estas crianças estão nas escolas e exigem do professor novas práticas pedagógicas que as insira em uma variedade de espaços sociais, não se limitando, mas incluindo o espaço escolar (DORNELLES, 2005). Os alunos começam a usar o computador e a internet antes dos 2 anos de idade, modificando o seu modo de pensar e a forma como aprendem.

Tais mudanças exigem do professor práticas pedagógicas inovadoras que possam dar conta destas demandas, pois, para estas crianças, os assuntos/conteúdos não se encontram isolados, e, sim, ligados a temas correlatos. Farah (apud MELLO \&

1 Informações disponíveis em: http://www.rived.mec.gov.br/site_objeto_lis.php 
VICARIA, 2007), afirma que esta nova geração articula idéias de forma mais rápida, abandonando a lógica linear, com começo, meio e fim.

Entretanto, os professores ainda são imigrantes digitais, com pouca intimidade com as tecnologias digitais e dificuldade para compreender seus recursos e funcionamento. Os imigrantes digitais, segundo Prensky (2001) são usuários do computador que ainda o veem como novidade, precisam de mídias impressas e relacionam-se na rede apenas com conhecidos.

Logo, essas particularidades da relação do professor com as novas tecnologias interferem no seu trabalho com a ciberinfância. A inserção da tecnologia, na prática pedagógica do professor, exigirá dele um novo olhar sobre a construção de conhecimento dessas crianças, para as quais a qualidade das relações e interações serão importantes na sua aprendizagem. Parte-se da concepção de que o ato pedagógico é intencional e, por isso, prevê procedimentos indispensáveis, como estudo, planejamento, aplicação ou método, avaliação/reflexão (ZABALA, 1998). A prática pedagógica articula diferentes elementos sociais, culturais e pedagógicos, os quais precisam ser olhados pelos professores de forma especial, pois a relação entre esses elementos interfere no trabalho docente significativamente.

Nesta perspectiva, a formação dos professores pode ajudá-los a formular um novo olhar sobre suas práticas pedagógicas, considerando o uso das tecnologias na educação e sua implicação no processo de construção de conhecimento destas crianças. Este paradigma aponta para a necessidade de promover mudanças urgentes nas formas de se pensar a educação por parte destes profissionais, de modo que estes possam refletir sobre o seu fazer pedagógico. Desta forma, poderão proporcionar ao aluno uma aprendizagem mais ativa, na qual o foco é a construção de seu conhecimento, criando significados por meio de vivências, exploração, manipulação e interação.

Entende-se que a escola e os professores possuem dois desafios principais neste novo contexto: fazer da escola um lugar mais atraente para os alunos e fornecer a eles subsídios para uma compreensão verdadeira da sociedade da informação (SANTOS, 2006). Assim, esta deve ser um lugar onde a aprendizagem é construída e não um espaço onde o professor apenas transmite conhecimento. Sem dúvida, o computador desperta a curiosidade e motiva as crianças a buscar novos conhecimentos, entretanto não basta apenas introduzir as Tecnologias da Informação e da Comunicação (TIC's) na escola, preservando as práticas tradicionais. É necessário mudar as práticas, fazendo com que essas se tornem significativas para os alunos e que despertem o interesse para a aprendizagem.

Logo, a importância do papel do professor se dá em um nível de orientação, da criação de contextos adequados e condições para o desenvolvimento, tanto na construção de modelos estratégicos quanto na atribuição de sentido que conduza a uma aprendizagem significativa. Assim, a formação do educador tem como objetivo possibilitar a participação deste na organização de novos processos na sala de aula, ampliando o campo das experiências deste professor.

Nesta perspectiva, acredita-se que a educação continuada de professores de Educação Infantil e Ensino Fundamental apresenta-se como um dos caminhos possíveis para uma educação de qualidade. A seguir, pretende-se apontar o potencial dos objetos de aprendizagem para enriquecer o trabalho pedagógico do professor em serviço, qualificando sua atuação.

\section{Objetos de aprendizagem}


Objeto de Aprendizagem é qualquer recurso digital como, por exemplo: textos, animação, vídeos, imagens, aplicações, páginas $W e b$ em combinação que se destinam a apoiar o aluno no processo de aprendizagem. São recursos digitais modulares, usados para apoiar a aprendizagem presencial e à distância. Os OAs podem ser reutilizados em ambientes virtuais de aprendizagem ou mesmo em sites para educação, aprendizagem e treinamento, tanto presencialmente, quanto a distância (IEEE, 2005; WILEY, 2000 apud TAROUCO, 2006). Essa perspectiva visa, entre outros fatores, reduzir o custo na produção de materiais pedagógicos, gerando interesse dos educadores, inclusive na sua construção.

Através da pesquisa na $W e b$, podem ser agregados materiais gratuitos e livres ao objeto com facilidade, como também reutilizar outros, adaptando-os ao seu contexto educacional. De qualquer forma, o planejamento é fundamental na produção dos OA. Para isso, segundo Amante e Morgado (2001) deve-se tratar, primeiramente, da concepção do projeto que consiste na seleção da idéia/tema, da equipe, dos conteúdos, dos objetivos pedagógicos, do público-alvo, do tipo de aplicação e do contexto. Em seguida, deve-se partir para a planificação (seleção e organização dos conteúdos, mapa geral do objeto, interface, navegação, storyboard, ajustes). Por fim, faz-se necessário implementar (desenvolvimento propriamente dito) e avaliar o material. Os objetos de aprendizagem, para serem considerados como tal, devem permitir acesso e uso em locais e plataformas diferentes, neste último caso, sem necessidade de reformulação (FABRE et al, 2003 apud TAROUCO et al, 2004). Outra vantagem de se utilizar os objetos para desenvolver conhecimentos/conteúdos é a possibilidade de acoplar recursos multimídia, tais como som, imagem, vídeo, simulações etc. Esses recursos dinamizam a forma de apresentação e de manipulação dos conteúdos, possibilitando outras possíveis construções de conhecimento pelos sujeitos.

Nesta perspectiva, entende-se que este recurso pode auxiliar o professor em sua ação docente, pois oferece diferentes ferramentas que servem de apoio ao processo de aprendizagem. A utilização de elementos multimídia, tais como simulações, imagens, textos, som, animações e vídeos, desempenham um papel importante na aquisição de conhecimento quando bem utilizadas. Estes podem ser considerados como recursos pedagógicos que permitem ao aluno acompanhar o conteúdo de acordo com o seu próprio ritmo, acessando facilmente a informação e se engajando de forma independente e autônoma num aprendizado por descoberta. As ferramentas comunicacionais, como, por exemplo: chats, fóruns de discussões, e-mails e blogs potencializam o processo de interação entre sujeitos, aumentando o grau de envolvimento das pessoas e, como consequiência, elevam o grau de conscientização sobre o próprio processo de desenvolvimento cognitivo e a relação deste com o contexto social.

Os objetos de aprendizagem foram desenvolvidos, neste estudo, em Flash 8 e possuem diferentes recursos multimídia. Os materiais encontram-se disponíveis nos sites $^{2}$ dos grupos de pesquisa participantes do projeto e em DVD, para quem não tem acesso à Internet. E também, como já citado, estão cadastrados no repositório CESTA para multiplicar as discussões e o conhecimento sobre essas temáticas e torná-las reusáveis. Nesse repositório não há necessidade de seguir um padrão determinado, apenas se deve preencher um formulário eletrônico com as especificações do material.

2 NUTED - http://www.nuted.edu.ufrgs.br/ei e GEIN - http://www.ufrgs.br/faced/gein 


\subsection{A construção de objetos para a formação de professores}

Para a construção dos objetos de aprendizagem, procura-se seguir algumas etapas, baseadas nos estudos, de Amante e Morgado (2001) e nas experiências da equipe. Assim, os objetos de aprendizagem foram construídos, a partir das seguintes etapas: concepção, planejamento, implementação e avaliação. Para isso, foram realizadas reuniões semanais entre a equipe. Dentre essas etapas, destacam-se os processos de levantamento e desenvolvimento de material bibliográfico e multimídia para compor o conteúdo educacional dos objetos de aprendizagem; o desenvolvimento do storyboard ${ }^{3}$; planejamento e implementação da interface gráfica de cada um dos protótipos necessários para chegar a interface final de cada objeto,; levantamento de critérios de usabilidade do Design da interação, Design da apresentação e Design da Informação; implementação propriamente dita dos objetos de aprendizagem e, por último, a inserção dos objetos dentro repositório CESTA.

Em geral, todos os OAs apresentados nesta abordagem exploram temas da ciberinfância e práticas pedagógicas utilizando recursos digitais. Apresentam material didático para pesquisa, desafios, glossário, guia e biblioteca digital. Propõe-se que a maioria dos desafios (atividades) sejam realizados em ferramentas da Web, tais como blog, Pbworks, fórum, editor de slides, ambientes virtuais de aprendizagem, entre outras. Com isso, pensa-se em provocar trocas de idéias e materiais, além da publicação e comunicação acessível e da possibilidade de busca permanente. A seguir, apresentamse esses objetos.

\subsubsection{Objeto de Aprendizagem: Ciberinfância ${ }^{4}$}

O primeiro OA partiu de uma necessidade de abordar e conhecer melhor as crianças que lidam facilmente com tecnologia, chamado de Ciberinfância (DORNELLES, 2005). A visibilidade deste tema está ampliando-se cada vez, pois esse aparece na mídia e é parte da preocupação de alguns professores e pais. Esse tema é abordado no OA através da história das infâncias, dos aspectos socioculturais e da área da saúde e de suas relações com a sociedade informatizada. A interface gráfica desse OA é uma sala com objetos que compõem lan houses, quartos infantis e salas de escolas de Educação Infantil. Os desafios apresentam material multimídia e propõem, entre outras opções, a pesquisa e elaboração de artigos e projetos.

\subsubsection{Objeto de Aprendizagem: Arquiteturas Pedagógicas para Educação Infantil ${ }^{5}$}

A compreensão sobre o que significa "arquitetura pedagógica" é fundamental para o uso de ambientes virtuais na Educação. Esse OA tem o objetivo de discutir planejamento pedagógico na Educação Infantil, ambientes virtuais de aprendizagem (AVA) e arquiteturas pedagógicas, bem como possibilitar a compreensão sobre as Arquiteturas Pedagógicas (AP) e sua aplicação no fazer pedagógico na Educação Infantil. Para

3 Documento estruturado em sequências e com indicações técnicas destinadas a orientar a produção do objeto de aprendizagem

4 Esse objeto de aprendizagem encontra-se na página:

http://www.nuted.edu.ufrgs.br/objetos/ei2006/ciberinfancia/index.html

5 Esse objeto encontra-se na página: http://www.nuted.edu.ufrgs.br/objetos/ei2006/ap/index.html 
discutir esse tema, estruturou-se o OA Arquiteturas Pedagógicas para Educação Infantil em módulos, quais sejam, Educação Infantil, AVA e Arquiteturas Pedagógicas. A metáfora da interface gráfica foi representada por uma escola. Ao "entrar" nela, encontra-se um corredor com três portas destinadas a cada módulo, os quais podem ser explorados livremente. O material de apoio e o glossário aparecem de forma permanente no menu do objeto. Nos módulos, encontra-se o "Depósito de Ferramentas" o qual possui indicações de softwares, AVA e lista de "links interessantes".

\subsubsection{Objeto de Aprendizagem: Produzindo Infâncias ${ }^{6}$}

Neste OA, buscou-se debater questões históricas, sociais, culturais e políticas que, de alguma forma, produzem as infâncias. Com isso, pode-se colaborar para a reflexão sobre aspectos que surgem nas rotinas com crianças e que apontam a constituição de diferentes infâncias. Na metáfora, buscou-se criar um cenário que remetesse a essa produção na contemporaneidade por meio da interface gráfica composta de um baú iluminado. Desse baú saem fotos de crianças com objetos/situações (antigos e novos), que podem produzir as infâncias. As telas que compõem o objeto seguem o mesmo padrão de interface, utilizando cor de destaque às palavras importantes.

\subsubsection{Objeto de Aprendizagem: Outras Infâncias ${ }^{7}$}

O objeto de aprendizagem Outras Infâncias traz as discussões acerca de outros tipos de infâncias que se encontram no contexto das grandes cidades brasileiras: (1) a infância das crianças em situação de rua, (2) em situação de risco, (3) a infância "executiva" das crianças, as quais têm muitas atividades no seu cotidiano e (4) a infância trabalhadora. Logo, a discussão fundamental pressupõe uma compreensão de que não existe apenas uma infância, ou seja, não há uma infância universal e ideal, mas infâncias reais e diversas em contextos também diversos. O objeto foi desenvolvido em HTML, e sua metáfora remete aos sites de jornais e revista. Cada desafio é independente, podendo ser utilizados separadamente ou o conjunto deles. O professor pode indicar outros textos, animações, vídeos de acordo com sua prática pedagógica.

\subsubsection{Objeto de Aprendizagem: FORMSIM - Formação do Símbolo na Criança ${ }^{8}$}

Este objeto de aprendizagem trata do tema "A Formação do Símbolo na Criança", o qual é inspirado no nome de uma das obras de Jean Piaget (1978). Esse pesquisador procurou descrever como os sujeitos constroem conhecimento, por meio das suas observações e entrevistas, utilizando-se do Método Clínico. No caso desse objeto, busca-se compreender como se dá a formação do símbolo, propondo aos usuários que experimentem situações de aprendizagem acerca desse tema. Sugere-se que se utilize um AVA para organizar os registros e potencializar as trocas, quando a exploração do material for realizada em grupo de estudo ou em cursos de graduação e pós-graduação.

\subsubsection{Objeto de Aprendizagem: Espaços digitais na ciberinfância9}

\footnotetext{
Produzindo Infâncias está disponível em: http://www.nuted.edu.ufrgs.br/objetos/ei2006/pi/index.html Outras Infâncias está disponível em: http://www.nuted.edu.ufrgs.br/objetos/ei2007/infancias/index.html

FORMSIM está disponível em: http://www.nuted.edu.ufrgs.br/objetos/ei2007/FORMSIM/index.html Espaços digitais na ciberinfância está disponível em:
} 
Esse OA trata da temática da ciberinfância e de artefatos tecnológicos, a fim de compreender as relações existentes entre as crianças e os espaços digitais e como elas se constituíram historicamente. Para isso, realizou-se uma contextualização dos artefatos tecnológicos na infância e, também, um levantamento sobre softwares, jogos e sites que interessam às crianças, a fim de refletir sobre os "efeitos" desses artefatos na constituição da infância. Nos desafios do OA, propõe-se que seja criada, ao longo do uso do objeto, uma linha do tempo, procurando situar e compreender alguns acontecimentos. Os desafios também fazem um convite à reflexão sobre o processo de apropriação tecnológica das crianças e dos seus efeitos, já que propõem que sejam realizadas pesquisas em sites infantis, buscando refletir sobre as narrativas e imagens endereçadas às crianças. O conteúdo é dividido em três módulos, nos quais se encontram textos, desafios e entrevistas e outras informações organizacionais e explicativas nos links: Guia, Glossário e Midiateca.

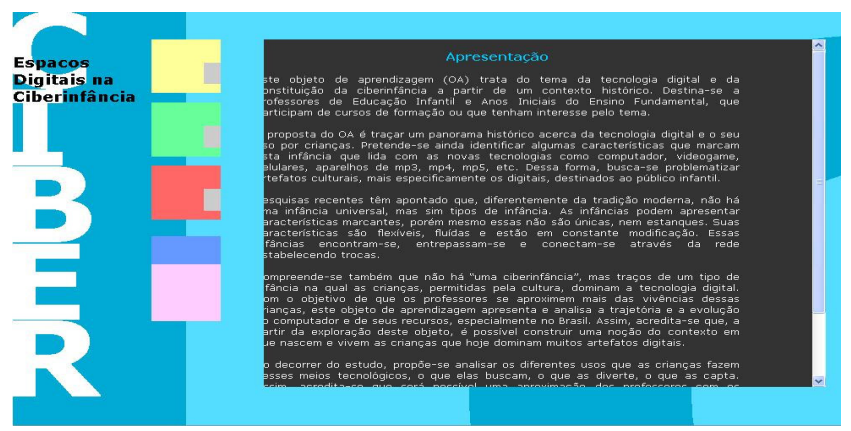

Figura 1 - Tela inicial do OA Espaços digitais na ciberinfância

\subsubsection{Objeto de Aprendizagem: Software Social na Educação Infantil ${ }^{10}$}

O principal objetivo desta proposta é proporcionar ao educador infantil um novo olhar sobre suas práticas pedagógicas, enfocando o uso/aplicação do software social no espaço pedagógico da Educação Infantil. Assim, este objeto terá como conteúdos principais: (1) a metamorfose da sala de aula atual; (2) o novo perfil dos alunos/professores; (3) apresentação de diversos softwares sociais que podem ser usados com crianças e (4) formas de construção/formulação de propostas pedagógicas utilizando software social. Para tanto, serão elaboradas apresentações, textos e vídeos que facilitem a compreensão do usuário do objeto sobre o tema. A metáfora visual e as atividades em forma de desafios proporcionarão uma aprendizagem autônoma e reflexiva, baseada na ação e reflexão sobre a ação de seu trabalho em sala de aula, buscando se vislumbrar uma articulação entre teoria e a prática para a melhoria do processo ensino-aprendizagem. 


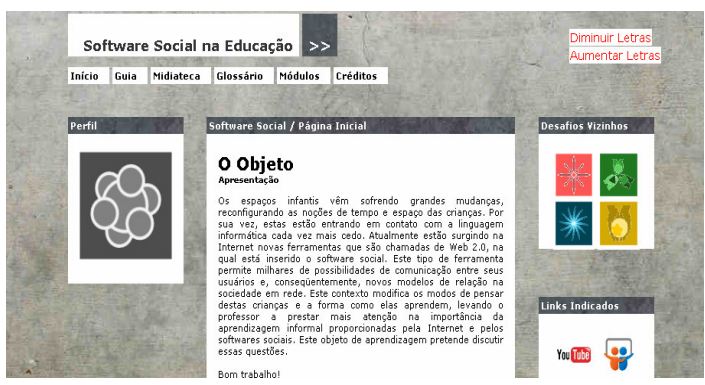

Figura 2 - Tela inicial do OA Software Social na Educação infantil

\subsection{Cursos de formação de professores e validação dos Objetos de aprendizagem}

A fim de capacitar professores para a ciberinfância, através dos objetos de aprendizagem, foram realizadas três ações de extensão. Cerca de 50 professores em exercício já foram formados nos cursos descritos a seguir. A ação de extensão PLANETA ROODA: planejando novas práticas pedagógicas em ambientes virtuais de aprendizagem foi realizada em 2006 e visou promover a instrumentalização de professores de escolas dentro e fora dos centros urbanos, através de projetos de extensão presenciais ou à distância. Como proposta, pretendeu-se incentivar a inclusão das tecnologias da informação e da comunicação no cotidiano da escola. Esta primeira ação, motivou a construção dos primeiros OAs descritos neste artigo e que foram utilizados e validados na ação seguinte.

Intitulada Oficina de Arquiteturas Pedagógicas para Educação Infantil, esta ação de extensão configurou-se como primeira experiência de validação e formação de professores através de OAs desenvolvida pelo NUTED. A ação foi realizada em 2007 e utilizou os OAs Arquiteturas Pedagógicas para a Educação Infantil, Produzindo Infâncias e Outras Infâncias.

Através dos cursos foi possível conhecer melhor as dificuldades e interesses dos professores em relação ao uso da tecnologia na escola. Pode-se observar isso em alguns depoimentos dos professores-alunos nos fóruns, abertos no AVA PLANETA ROODA, para discussão durante o curso. Veja:

A utilização do computador com meus alunos sempre foi um sonho para mim, que agora têm chegado cada vez mais perto da realidade. É através das Arquiteturas Pedagógicas que poderemosmos repensar nossas práticas atuais e pensar em práticas inovadoras e novas formas de se trabalhar com nossos alunos, não só no laboratório de informática, como também em nossa sala de aula, sob um novo olhar, um novo enfoque, uma nova perspectiva (Aluna J. Mensagem do Fórum intitulado Arquiteturas Pedagógicas na Educação Infantil em 19/11/2007).

Em 2008, foi realizado o curso "Uso do Planeta Arte: formação de professores de Educação Infantil e Séries Iniciais". O projeto foi planejado a partir da necessidade de dar continuidade à capacitação de professores da Educação Infantil e dos Anos Iniciais do Ensino Fundamental, para a utilização das tecnologias na ação pedagógica. No final das aulas, era solicitado que as alunas escrevessem na funcionalidade Diário do PLANETA ROODA a fim de refletir sobre suas aprendizagens. A seguir, tem-se um exemplo: 
um melhor ensino- aprendizagem. Aprendemos como os jogos simbólicos, de construção e de regras influenciam positivamente dentro da sala ou fora dela. As colegas presentes relataram inumeros trabalhos que foram aplicados em seus alunos,ou em suas escolas, e obtiveram resultados surpreendentes. através dos jogos, brincadeiras. As experiências de aprendizagens foram muito gratificantes (Aluna I. - Mensagem no Diário em (1/05/2008).

Nas falas dos professores registradas no ambiente virtual, pode-se observar que o curso proporcionou reflexões acerca da ação pedagógica junto à ciberinfância como uma prática que deve envolver o uso das tecnologias e da linguagem informática, mas sem esquecer das múltiplas linguagens na Educação Infantil. Portanto, é importante compreender a criança como um agente social, que interpreta seu mundo e sua vida de forma particular, através de múltiplas interações simbólicas estabelecidas pelas crianças entre si, com adultos e com os espaços digitais.

\section{Considerações finais e perspectivas}

A partir dessas experiências, é possível verificar o quanto é importante desenvolver materiais digitais destinados à formação de professores de Educação Infantil e Séries Iniciais, já que é notável uma carência de materiais disponíveis na Internet com essa finalidade. Os cursos também apontaram isso, pois os participantes demonstraram muito interesse e curiosidade pelas temáticas dos objetos, por serem essas muito atuais e por perpassarem seu trabalho em sala de aula.

Os espaços digitais da ciberinfância podem ser entendidos como os recursos informáticos que permitem interação e comunicação entre sujeitos e sujeito-objeto. Por isso, esses espaços têm inúmeras possibilidades educativas. Essas possibilidades foram pensadas e verbalizadas pelas professoras/alunas durante os cursos. A vivência no espaço digital tornou-se significativa para as professoras/alunas, à medida essas se apropriavam das ferramentas e visibilizavam o uso dessas últimas em suas práticas pedagógicas. De acordo com Nevado (2004), quando a formação do professor enfatiza a sua experiência, este passa a incorporar a inovação que lhe foi apresentada, buscando transformar a sua prática de modo significativo. Logo, as vivências das professoras/alunas nos espaços digitais das crianças e a dinâmica dos desafios dos objetos, a partir de sua prática, contribuíram para que ocorressem mudanças significativas na maneira de pensarem sua prática em sala de aula.

Dando continuidade ao trabalho de produzir OAs e formar professores a partir desses, encontra-se em desenvolvimento outros dois objetos de aprendizagem a partir do projeto "Professor 2.0: buscando práticas criativas na Web"11. Com esses OAs, buscar-se-á aprofundar questões inovadoras, como a Web 2.0 na escola. O objetivo é fornecer subsídios para os professores pensarem práticas pedagógicas que utilizem apropriadamente e criativamente esta nova geração de softwares disponíveis na rede. Para isso, estamos pesquisando fundamentos pedagógicos que fundamentem as práticas pedagógicas com recursos digitais, que promovam a criatividade de professores e alunos no uso desses recursos e que sirvam como referência de softwares e sites encontrados na rede para o trabalho educativo.

Paralelamente a isso, foi criado um curso de extensão chamado "Práticas pedagógicas para ciberinfância", através da UFRGS, a fim de oferecê-lo nesta instituição ou nas próprias escolas. Assim, objetiva-se dar continuidade ao trabalho de

11 Projeto aprovado pelo Edital 11/2009, promovido pela Secretaria de Educação a Distância Sead/UFRGS. 
formação de professores e coletar dados sobre a relação das escolas e a tecnologia, qualificando, com isso, nossos próximos OAs. Tem-se realizado parcerias com Escolas públicas e particulares de Porto Alegre oferecendo novos cursos de formação continuada de professores.

\section{Referências}

Amante, L. e Morgado, L., (2001). Metodologia de Concepção e Desenvolvimento de Aplicações Educativas: o caso dos materiais hipermedia. In: Revista Discursos: língua, cultura e sociedade, Portugal, v. 3, n. especial, p. 27-44.

Behar, Patricia. et al. Objetos de aprendizagem para educação a distância. In: Modelos pedagógicos em educação a distância. Porto Alegre: Artmed, 2009.

Dornelles, Leni Vieira. Infâncias que nos escapam: da criança na rua à criança cyber. Petrópolis: Vozes, 2005.

Mello,K.; Vicaria, L. Os filhos da era digital. In: Revista Época, 10 de set., 2007. p. 82-90.

Nevado, Rosane A. Novos Possíveis na formação de professores. In: Franco, Sérgio R. K. (org.) A Informática na Educação: estudos interdisciplinares. - Porto Alegre: Editora da UFRGS, 2004.

Piaget, Jean. A formação do símbolo na criança : imitação, jogo e sonho, imagem e representação. 3. ed. Rio de Janeiro: Zahar, 1978.

Prensky, Marc. Digital natives, Digital immigrants. On the Horizon. United Kingdom, MCB University Press, v. 9, $\mathrm{n}^{\mathrm{o}}$ 5. 2001. Disponível em: http://www.marcprensky.com/writing/Prensky\%20\%20Digital\%20Natives,\%20Digital\%20Immigrants\%20-\%20Part1.pdf

Tarouco, L. Objetos de Aprendizagem para M-Learning. In: Anais do Congresso Nacional de $\begin{array}{lllll}\text { Tecnologia } & d a & \text { Informação } & \text { Comunicação, } & \text { Brasil, }\end{array}$ http://www.cinted.ufrgs.br/CESTA/objetosdeaprendizagem_sucesu.pdf, Setembro, 2004.

Tarouco, L. Objetos de Aprendizagem”, In: FÓRUM EAD, Brasil, http://www.ufrgs.br/sead/arquivos/objetosdeaprendizagem_liane.pdf, Setembro, 2006.

ZABALA, Antoni. A prática educativa: como ensinar. Ernani Rosa (Trad.). Porto Alegre: Artmed, 1998. 